\title{
Research on Design of Sports Teaching Information Management Platform based on B/S Model
}

\author{
Jingfang Chen ${ }^{1}$, Zhiling Chen ${ }^{2}$ \\ ${ }^{1}$ School of Physical Education, Daqing Normal University, Daqing, 163712, China \\ ${ }^{2}$ School of Physical Education, Liaoning Normal University, Dalian, 116029, China
}

Keywords: B/S framework, VB programming, Sports teaching, Management platform, Communication port, Editor, LED display.

\begin{abstract}
This paper established the B/S frame mathematical model, combined with VB programming algorithm, carries on the design of the sports teaching information platform, finally a new physical education teaching ranking method is obtained, and this algorithm is used to realize correlation analysis of student achievement. This paper designs teachers end, students end and the central processing end of sports teaching information management platform, and uses central processing unit, memory and I/O export functions to design the platform, finally the multi-function sports teaching management platform is obtained. Using sports information management platform, this paper designs the relevance of teaching achievements, which provides technical support for the research on the teaching of physical education.
\end{abstract}

\section{Introduction}

Physical education teaching is very important part of higher school informatization and automation, and physical education teaching is produced under this kind of background. The use of computer in the physical education teaching has changed the traditional teaching mode and improved the efficiency of teacher. The B/S framework uses multilayer relations to build model structure, which realizes the correlation integration transparent access between data, so it can be applied in data mining of sports teaching information management information system [1, 2]. This paper uses multi-layer B/S computer framework model to design physical education teaching system, which realizes the innovative design of physical education teaching platform. It provides a new computer method for the design of physical education teaching information management system.

\section{Overview of the Sports Teaching System B/S Framework}

The introduction of the $\mathrm{B} / \mathrm{S}$ framework in physical education teaching system is mainly applied in the data mining of teaching information. The process is mainly using data algorithm. The principle of algorithm is using membership function to search the correlation data [3]. In the sports teaching system, management and analysis of student information data is one of the most important parts. This paper uses the B/S framework model to design teaching information management system, and the main process is as shown in Figure 1.

Figure 1 shows a schematic diagram of the design of the sports teaching B/S framework structure. The teaching information management mainly uses the B/S structure, and uses the technology of MD5 to encrypt input passwords. If the password is correct, the students' information management system can be access [4]. The management system is mainly used C\#.NET programming. 


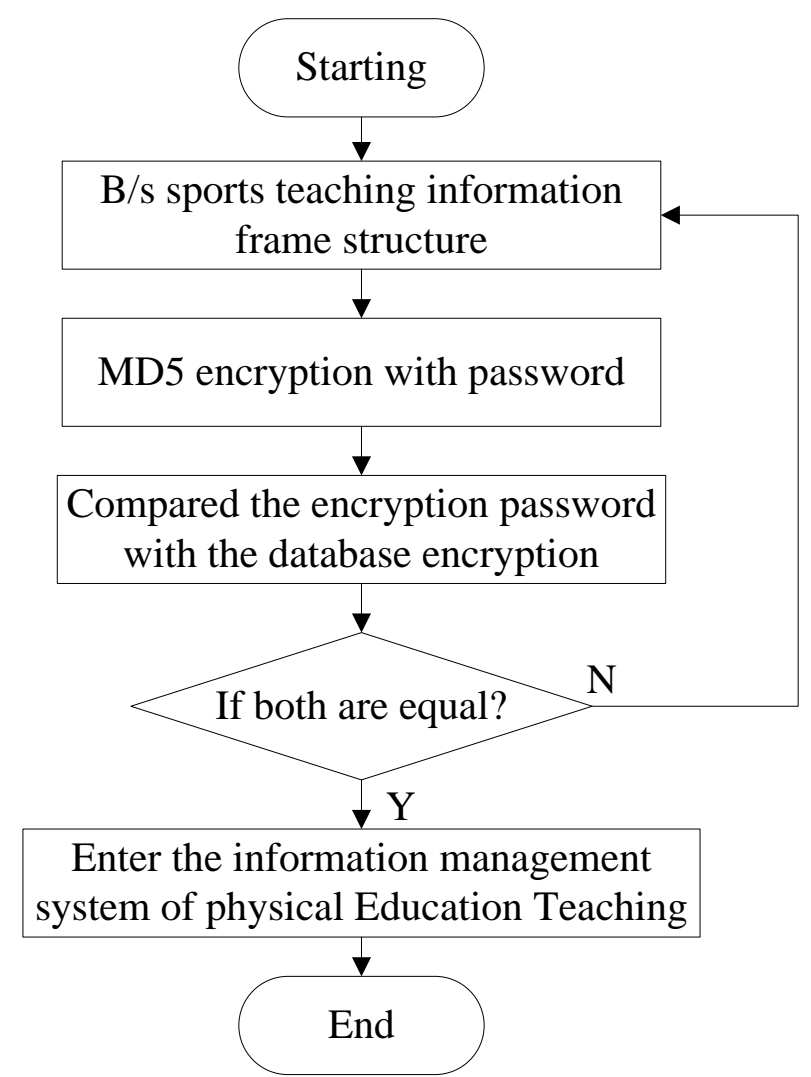

Fig. 1 B/S frame structure schematic diagram of physical education teaching

\section{Mathematical Model and Algorithm of B/S Framework Sports Teaching Performance Management Platform}

In order to study correlation between sports teaching management and performance, this paper firstly divide exercise score results into three grades, respectively first, second, third grade. It uses eight quintile statistics to get membership function, so as to establish the correlation degree of sports teaching achievement management actions and results [5-7]. The main steps of eight quintile method are as follows:

Assume the computer statistics score is $F$, average divided into grades can be expressed as $F$ / 8 , the first can be expressed as $F$, the second can be expressed as $2 F, \cdots$, the seventh can be expressed as $7 F$.

The calculation method of membership function correlation degree can be expressed in Table 1 .

Table 1. The membership functions set statistical

\begin{tabular}{|c|c|c|}
\hline Statistical score grade & Score range & Median numerical \\
\hline First grade & $0-3 F$ & $F$ \\
\hline Second grade & $1 F-5 F$ & $3 F$ \\
\hline Third grade & $3 F-\max$ & $5 F$ \\
\hline
\end{tabular}

The membership function of third grade sports achievement statistics score is:

$$
P_{1}(a)=\left\{\begin{array}{rll}
1.0, & \text { if } \quad a<F \\
\frac{2 F-a}{2 F-F}, & \text { if } \quad F<a<2 F . \\
0, & \text { if } \quad a>2 F
\end{array}\right.
$$

The membership function of first grade sports achievement statistics score is: 


$$
P_{2}(a)=\left\{\begin{aligned}
1.0, & \text { if } \quad a<4 F \\
\frac{a-4 F}{5 F-4 F}, & \text { if } \quad 4 F<a<5 F . \\
0, & \text { if } \quad a>5 F
\end{aligned}\right.
$$

The membership function of second grade sports achievement statistics score is:

$$
P_{3}(a)=\left\{\begin{array}{rl}
0, & \text { if } \quad a<F \\
\frac{a-F}{2 F-F}, & \text { if } \quad F<a<2 F \\
1.0, & \text { if } \quad 2 F<a<4 F \\
\frac{5 F-a}{5 F-4 F}, & \text { if } \quad 4 F<a<5 F \\
0, & \text { if } a>5 F
\end{array} .\right.
$$

Significant coefficient between body back angle, initial velocity, angle shot and sports performance statistics score can be expressed as:

$$
C=\frac{\sum_{j=1}^{n} \sum_{i} \sum_{g}\left[B_{i}\left(a_{j}\right) \times D_{g}\left(b_{j}\right)\right]}{n} .
$$

Where $C$ is the total number of athletes, $B_{i}$ is the membership function of $i$ grade, $D_{g}$ is membership function of the $g$ grade, $a_{j}$ is the students' original scores of $j$ project, $b_{j}$ is students' original score of $j$ project.

\section{Study on the Application of Computer in the Design of Sports Teaching Management Platform}

Figure 2 is time loss of designed algorithm. As shown in the figure, the consuming time of common algorithm is significantly larger than $\mathrm{B} / \mathrm{S}$ algorithm $[8,9]$. When the data is $15 \mathrm{~K}$, the consumed is the shortest, while the common algorithm uses 20s, and B/S framework uses 18s; when the data is $50 \mathrm{~K}$, the consumption time is longest, while the common algorithm uses $43 \mathrm{~s}, \mathrm{~B} / \mathrm{S}$ frame algorithm uses 37s; The largest gap is $10 \mathrm{~s}$, which proves reliability and validity of $\mathrm{B} / \mathrm{S}$ frame algorithm.

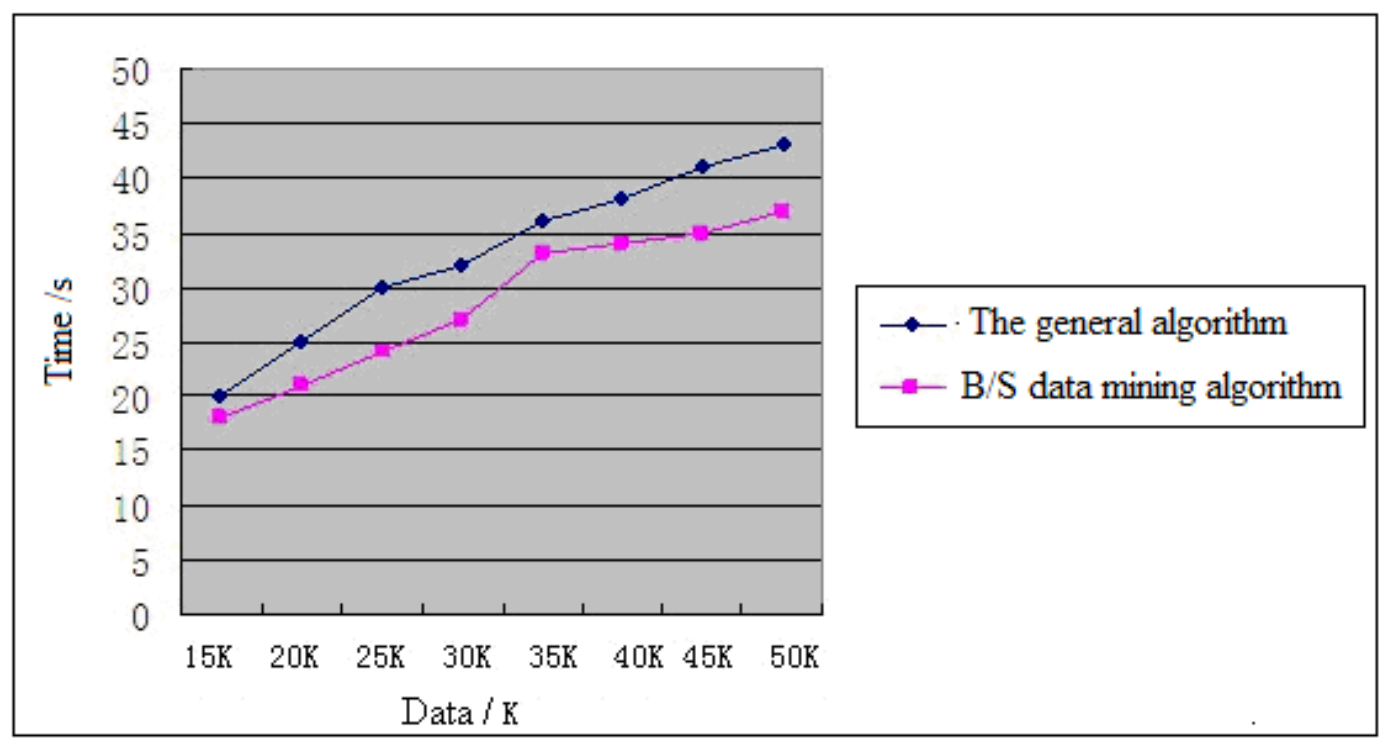

Fig. 2 Data calculation time

As shown in Figure 3, teaching interface mainly includes the drawing function, the function of data transmission and image re-draw function [10] In the image rendering process, the user can draw various forms using the brush function graphics, and the image can be presented to students in real-time through transmitting device. 


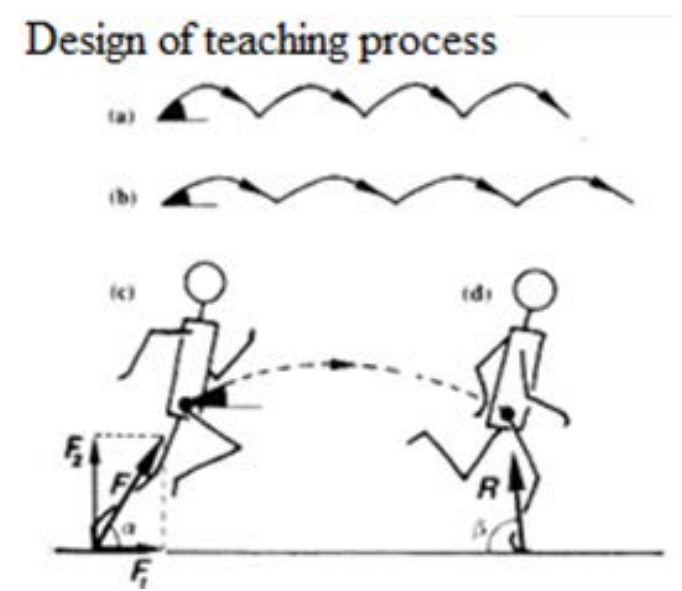

Fig. 3 Sketch visual function of teaching system interface

Table 2 shows student achievement grade correlation membership table using sports teaching information management platform [11]. Using the B/S frame model can classify statistics of student achievement, and can inspect the relevance of student achievement data in the correlation function, so it can be found the affect of students' performance on the overall performance, which provides a theoretical reference for the physical education teaching process.

Table 2. Association membership list

\begin{tabular}{|c|c|c|}
\hline The score grade & Rank & Value \\
\hline Fail & Min-B1 & B1 \\
\hline \multirow{2}{*}{ Good } & \multirow{3}{*}{ B1-B4 } & B2 \\
\cline { 3 - 3 } & & B3 \\
\cline { 3 - 3 } excellent & B3-max & B4 \\
\hline
\end{tabular}

\section{Summary}

Combining VB programming this paper uses multilayer B/S framework model to carry out innovative design of $\mathrm{PE}$ teaching platform, and obtains the $\mathrm{B} / \mathrm{S}$ framework of sports teaching management platform. Sports teaching information management platform mainly comprises teacher end, a central processor and student terminal. The communication interface is mainly composed of the editor and the computer. The teachers end input includes computer button, sensor. The core part of the system is the central processing unit and sports teaching memory. Through the I/O port, the student end analyzes and displays the teaching sound and video signal using LED or LCD. Finally this paper designs on the data analysis and transfer function of sports teaching information platform, and obtains the information throughput curve changing with time, which provides a new method for computer research on the physical education teaching.

\section{References}

[1] G.G. Li, H. Chen and B. Yang. Data stream prediction query algorithm based on probability model. Computer science, 2012, 35 (4): 66-69.

[2] A.L. Chen, C.J. Tang, C.A. Yuan and M.F. Zhu. The compression algorithm of wavelet and data flow based on the coupling characteristics. Journal of software, 2012, 18(2): 177-184.

[3] X.L. Zhu, J. Lan, S.Q. Li and Y. Jia. Data flow anomaly detection based on tensor decomposition. Computer engineering and science, 2013, 31(6): 75-78.

[4] C.Y. Yang, J. Zhou. A mixed attribute data stream clustering algorithm. Journal of computers, 2011, 30(8): 1364-1371. 
[5] Y.Y. You, Y.S. Zhang and J.P. Zhang. SLFS fidelity evaluation based on improved SFAM multi classifier. Journal of system simulation, 2011, 3(5): 65-68.

[6] Q. Yue, S. Feng. Calculation performance analysis of genetic algorithm. Journal of computers, 2012, 32(12): 2389-2392.

[7] J.H. Li, M. Li and L.H. Yuan. The pseudo parallel genetic algorithm based on clustering. Pattern recognition and artificial intelligence, 2012, 22(2): 188-194.

[8] J. Zhuang, Q.Y. Yang, H.F. Du and D.H. Yu. An efficient and complex genetic algorithm. Journal of software, 2010, 2 (11): 2790-2801.

[9] S.W. Chen, M.D. Li. An improved genetic clustering algorithm and its simulation. Computer applications and software, 2012, 27(9): 100-102.

[10]K. Wang, X.S. Yan, J. Jin and Z.G. Zhan. An improved genetic K clustering algorithm. Computer and digital engineering, 2011, 38(1): 18-20.

[11]B. Wang, C.L. Duan, H. Wu and Y.G. Song. Research and application of fuzzy set and rough set. Beijing: Publishing House of electronics industry, 2011: 56-83. 